\title{
Physical Properties of Iranian Berhi Date at Different Stages of Maturity
}

\author{
Razieh Pourdarbani ${ }^{1}$, Hamid Reza Ghassemzadeh ${ }^{1}$, Hadi Seyedarabi ${ }^{2}$, \\ Fariborz Zaare $^{3} \&$ Mohmmad Moghaddam ${ }^{3}$ \\ ${ }^{1}$ Department of agricultural machinery engineering, University of Tabriz, Iran \\ ${ }^{2}$ Department of Electrical and computer engineering, University of Tabriz, Iran \\ ${ }^{3}$ Faculty of agriculture, University of Tabriz, Iran \\ Correspondence: Razieh Pourdarbani, Department of agricultural machinery engineering, University of Tabriz, \\ Iran. E-mail: r_pourdarbani60@yahoo.com
}

Received: March 29, 2012 Accepted: May 4, 2012 Online Published: July 30, 2012

doi:10.5539/sar.v1n2p268 URL: http://dx.doi.org/10.5539/sar.v1n2p268

\begin{abstract}
In the present study, some physical properties of the Iranian date (Berhi variety) were determined at three stages of maturity namely Khalal, Rotab and Tamar. Color and textural features of samples were extracted by image processing toolbox of Matlab software. Total soluble solids (TSS), $\mathrm{pH}$ and weight of samples were also measured. The relationship between color and TSS, surface area and weight were obtained. The maximum correlation between TSS content and color occurred in blue for Rotab and Tamar but in red for Khalal. In the meantime, color and textural features differences between three stages of maturity were significant. There was a linear relationship between weight and surface area. The weights and areas of Rotab and Tamar were significantly different from those of Khalal.
\end{abstract}

Keywords: date, Khalal, Rotab, physical properties, Tamar

\section{Introduction}

Date is one of the non-oil export products of Iran that play very important role in terms of increasing the assets of the country. Date is one of the rare fruits that all of its parts such as flesh, stone, leaf, etc. can benefit food supply chain if processed properly. Nearly 75 percent of the dried material of Date is sugar. Date fruits are known to be a source of iron, potassium, calcium, chlorine, copper and Sulphur. Also it contains A, B1 and B2 vitamins and Tarooneh water is extracted from outer cover of Date bunch that is used as tranquilizer. Ground stone of Date is included in animal diet. It is also worth to mention that leaf and branches of Date palm are used as raw materials in Paper mill and artifact industries. Confectioneries and processing industries are also among those sectors that can benefit from Date processing wastes (Rohani, 1988).

The first step in mechanizion of post-harvest operations related to Date, acquires a sound knowledge concerning its physical properties. Size and shape characteristics are most often used in sorting and sizing of fruits, and determining an appropriate size for packages and plastic bags used in date handling.

Akar and Aydin (2005) evaluated some physical properties of gumbo fruit varieties as a function of moisture content. Kashaninejad et al. (2006) determined some physical and aerodynamic properties of pistachio nut and its kernel as a function of moisture content in order to design processing equipment and facilities. Topuz et al. (2005) determined and compared several properties of four orange varieties. Keramat Jahromi et al. obtained some physical properties of Date (cv. Lasht) in 2007 and Date (cv. Behr and Khasoei) in 2008. Safa and Khazaei (2003) determined and modeled some physical properties of pomegranate fruits related to packaging.

In the present research, some physical properties of the Iranian Date (Berhi variety) were determined at three stages of maturity namely Khalal, Rotab and Tamar. Color and textural features of samples were extracted by image processing. Total soluble solids (TSS), $\mathrm{pH}$ and weight of samples were also measured. The relationship between color and TSS, surface area and weight were obtained. Compression tests were also performed to examine its firmness. In the meantime its relaxation behavior under constant displacement was evaluated and surface area of the fruit was determined for the purpose of heat and mass transfer modeling during storage period, cooling and drying operations. 


\section{Methods and Materials}

In this study, the date fruit samples were selected randomly from Berhi cultivar from Date research institute in Ahvaz (located in the south of Iran). The samples were at 3 stages of maturity namely Khalal (under mature), Rotab (semi mature) and Tamar (full mature). The fruits were taken to the Laboratory individually and were weighed one by one by a digital balance with $0.01 \mathrm{gr}$ accuracy. Then images of all samples were captured by an industrial digital camera (Telecam No.Nck 41CV) and a capture card (winfast 2000) and saved in personal computer. Total soluble solid (TSS) in the liquid extract of Date was measured by a refractometer (MASTER-53M) and was stated as Brix\%.

To obtain liquid extract of the Date, nearly $30 \mathrm{gr}$ of each sample was crushed uniformly by an electronic mixture. $100 \mathrm{ml}$ distilled water was added into the mixture and stored in $60^{\circ} \mathrm{C}$ water bath for 20 minutes. Finally, it was filtered. To measure the $\mathrm{pH}$ of Date samples, titration method was used. $5 \mathrm{ml}$ of liquid extract of sample was poured into Erlenmeyer flask that contained nearly $50 \mathrm{ml}$ of distilled water. Titration was performed by 2-3 drops of Phenolphthalein along with $0.1 \mathrm{NaOH}$. Acidity $(\mathrm{pH})$ of the sample was determined from the amount of $\mathrm{NaOH}$ used based on Malic acid.

The coefficients of friction between the product and galvanized steel surface were determined by using an inclined plane (Figure 1) as described by Nalbandi et al. (2011). The plane, containing a sample, was kept in its horizontal position in the beginning of test and then its inclination angle was increased gradually. As soon as slippage of the sample was observed, the angle of the plane was recorded. Tangent of the angle was reported as the coefficient of friction:

$\mu=\tan \varphi$

Where, $\mu$ is the coefficient of friction and $\varphi$ is the inclination angle of the friction surface.

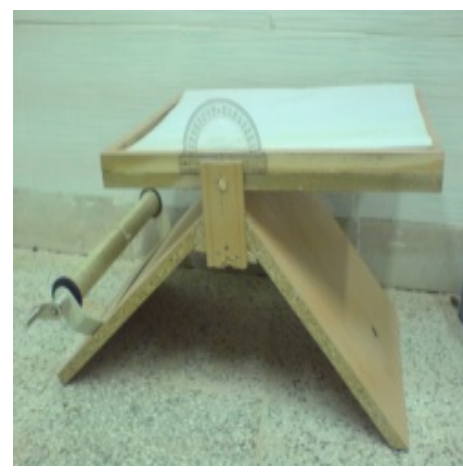

Figure1. Inclined plane for measuring the coefficient of friction

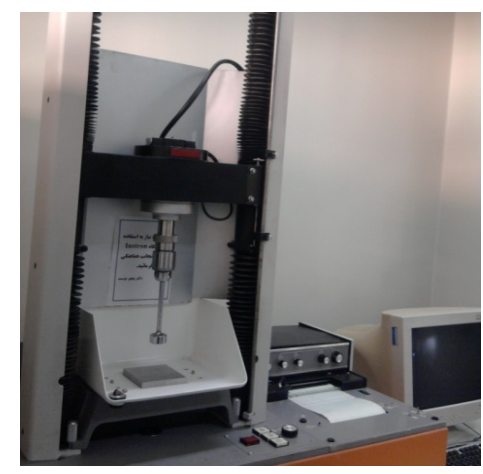

Figure 2. Instron model 1140 used in compression test

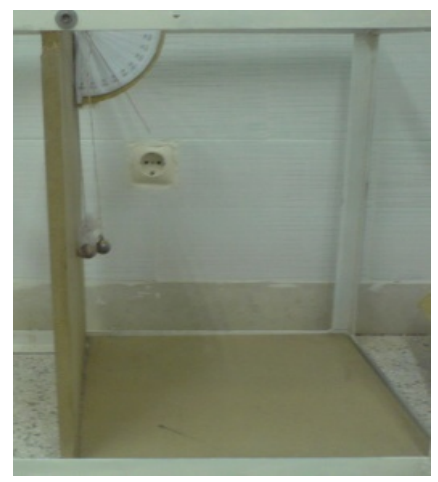

Figure 3. Pendulum ball for impact test

Compression test was performed by Instron, Model 1140 (Figure 2). All the samples were destoned and placed on flat base plate. $4.8 \mathrm{~cm}$ diameter moving plate was used in compression test. The crosshead speed of Instron was $200 \mathrm{~mm} \cdot \mathrm{min}^{-1}$ as described by Myhara et al. (2000). A $50 \mathrm{~N}$ capacity load-cell was used during the tests.

Impact test was performed by impact pendulum (Figure 3). A pendulum was used to apply predetermined impact energies to Date fruit. The samples were impacted by a steel ball ( $32 \mathrm{gr})$. A single Date was suspended in a cheesecloth pouch in a contact with a solid backstop. The pendulum was released as deflected $30^{\circ}, 45^{\circ}, 60^{\circ}$ and $90^{\circ}$ from its normal position, corresponding to impact energies of $0.00145,0.00317,0.0054$ and $0.0108 \mathrm{~J}$ respectively. The impact energy was calculated as follows:

$\mathrm{E}=\operatorname{mgr}(1-\cos \varnothing)$

where

$\mathrm{m}=$ mass,

$\mathrm{g}=$ acceleration due to gravity,

$r=$ length of pendulum, and

$\varnothing=$ angle of release. 
Eight fruits per treatment and maturity stage were used.

Drop tests from three heights namely 30,40 and $50 \mathrm{~cm}$ were performed on a solid steel metal. The selected samples of each stage of maturity had nearly uniform size and weight. Assuming an average weight, the equivalent impact energy levels were $0.0445,0.0415$ and $0.03 \mathrm{~J}$ for Khalal, Rotab and Tamar stages respectively. The drop energy was calculated as follows:

$\mathrm{E}=\mathrm{mgh}$

where

$\mathrm{m}=$ weight,

$\mathrm{g}=$ acceleration due to gravity, and

$\mathrm{h}=$ height.

Some other features of Date were extracted by image processing toolbox of Matlab software as shown in Table 1.

Table1. Some features extracted by image processing toolbox of Matlab

\begin{tabular}{|c|c|c|}
\hline Property & Description & Formula \\
\hline Contrast & $\begin{array}{l}\text { Returns a measure of the intensity } \\
\text { contrast between a pixel and its } \\
\text { neighbor over the whole image. }\end{array}$ & $\sum_{i, j}|i-j|^{2} p(i, j)$ \\
\hline Correlation & $\begin{array}{l}\text { Returns a measure of how correlated a } \\
\text { pixel is to its neighbor over the whole } \\
\text { image. }\end{array}$ & $\sum_{i, j} \frac{(i-\mu i)(j-\mu j) p(i, j)}{\sigma_{i} \sigma_{j}}$ \\
\hline Energy & $\begin{array}{l}\text { Returns the sum of squared elements in } \\
\text { the gray-level co-occurence } \\
\text { matrix(GLCM) }\end{array}$ & $\sum_{i, j} p(i, j)^{2}$ \\
\hline Homogeneity & $\begin{array}{l}\text { Returns a value that measures the } \\
\text { closeness of the distribution of } \\
\text { elements in the GLCM to the GLCM } \\
\text { diagonal. }\end{array}$ & $\sum_{i, j} \frac{p(i, j)}{1+|i-j|}$ \\
\hline Entropy & $\begin{array}{l}\text { Returns a measure of entropy of } \\
\text { grayscale image }\end{array}$ & $-\sum_{i} \sum_{j} p(i, j) \log _{2} p(i, j)$ \\
\hline$n$th moment & & $\mu_{n}(r)=\sum_{i=0}^{L-1}\left(r_{i}-m\right)^{n} p\left(r_{i}\right)$ \\
\hline average gray level & & $m=\sum_{i=0}^{L-1} r_{i} p\left(r_{i}\right)$ \\
\hline
\end{tabular}

\section{Results and Discussions}

For each test, adequate samples were selected. In order to extract the textural and apparent features, 50 samples from each stage of maturity were selected. The images of all samples were captured and analyzed using image processing of Matlab software. As indicated in Tables 2, 3 and 4, there were significant differences between Khalal, Rotab and Tamar in terms of Red and Green component intensities. But there were not significant differences between Rotab and Tamar in terms of Blue intensities. To use a new color space conversion and color distribution analysis techniques for date maturity evaluation, introduced by Lee et al. (2008), concentration should be made on Red and Green component intensities as the present findings suggest. 
Table 2. Result of Duncan test for red component

\begin{tabular}{|c|c|c|c|c|}
\hline \multirow{2}{*}{ Treatment } & \multirow{2}{*}{$\mathrm{N}$} & \multicolumn{3}{|c|}{ Subset for alpha $=0.05$} \\
\hline & & 1 & 2 & 3 \\
\hline Tamar & 50 & 136.8507 & & \\
\hline Rotab & 50 & & 150.0335 & \\
\hline Khalal & 50 & & & 204.6601 \\
\hline Sig. & & 1.000 & 1.000 & 1.000 \\
\hline
\end{tabular}

Table 3. Result of Duncan test for green component

\begin{tabular}{|c|c|c|c|c|}
\hline \multirow{2}{*}{ Treatmen } & \multirow{2}{*}{$\mathrm{N}$} & \multicolumn{3}{|c|}{ Subset for alpha $=0.05$} \\
\hline & & 1 & 2 & 3 \\
\hline Tamar & 50 & 106.4310 & & \\
\hline Rotab & 50 & & 116.4903 & \\
\hline Blue & 50 & & & 179.9518 \\
\hline Sig. & & 1.000 & 1.000 & 1.000 \\
\hline
\end{tabular}

Table 4. Result of Duncan test for blue component

\begin{tabular}{cccc}
\hline \multirow{2}{*}{ treatment } & $\mathrm{N}$ & \multicolumn{2}{c}{ Subset for alpha $=0.05$} \\
\cline { 3 - 4 } 3 & 50 & 85.4513 & 2 \\
\cline { 3 - 4 } 2 & 50 & 86.3799 & \\
1 & 50 & & 92.9505 \\
Sig. & & .239 & 1.000 \\
\hline
\end{tabular}

To determine $\mathrm{pH}$, total soluble solids (TSS) and Brix, 5 random samples were selected out of each 50 samples per stage. Table 2 shows that Rotab and Tamar are not significantly different in Brix $\%$, but $\mathrm{pH}$ varies significantly with the stage of maturiry (Table 5 and Table 6). Taste of the fruits is determined by the ratio of sugar level to $\mathrm{pH}$ level. The best time for harvesting the fruits is when the ratio of Brix to $\mathrm{pH}$ is fixed. Christensen et al. (2012) studied the effects of harvest date on Thompson seedless grapes and raisins.

Table 5. Result of Duncan test for brix \%

\begin{tabular}{cccc}
\hline \multirow{2}{*}{ Treatment } & $\mathrm{N}$ & \multicolumn{2}{c}{ Subset for alpha $=0.05$} \\
\cline { 3 - 4 } & & 3.1400 & 2 \\
\hline Kalal & 5 & & 7.3200 \\
Rotab & 5 & & 7.3400 \\
Tamar & 5 & 1.000 & .973 \\
Sig. & & & \\
\hline
\end{tabular}


Table 6. Result of Duncan test for PH

\begin{tabular}{cccc}
\hline \multirow{2}{*}{ Treatment } & $\mathrm{N}$ & \multicolumn{2}{c}{ Subset for alpha $=0.05$} \\
\cline { 3 - 4 } & & 1 & 2 \\
\hline Khalal & 5 & .6400 & \\
Tamar & 4 & 1.0125 & 1.0125 \\
Rotab & 5 & & .4500 \\
Sig. & & .278 & .207 \\
\hline
\end{tabular}

Brix\% plotted versus RGB using Excel and the relation between RGB and \%Brix was obtained. In Rotab and Tamar, the maximum correlation occurred in Blue. But in Khalal, the maximum correlation occurred in Red (Figures 4, 5 and 6). Date sugar content is considered as a fruit commercial characteristic where it is important for both fresh consumption and fruit processing. Fadel et al. (2001) and Fadel et al. (2006) studied color properties of date fruits and introduced a computer-based method for date sugar content estimation. This method depends on calculating the intensities of the red, green, and blue components of fruit color via image processing algorithm. Color ingredients intensity was correlated to glucose, fructose and sucrose levels.

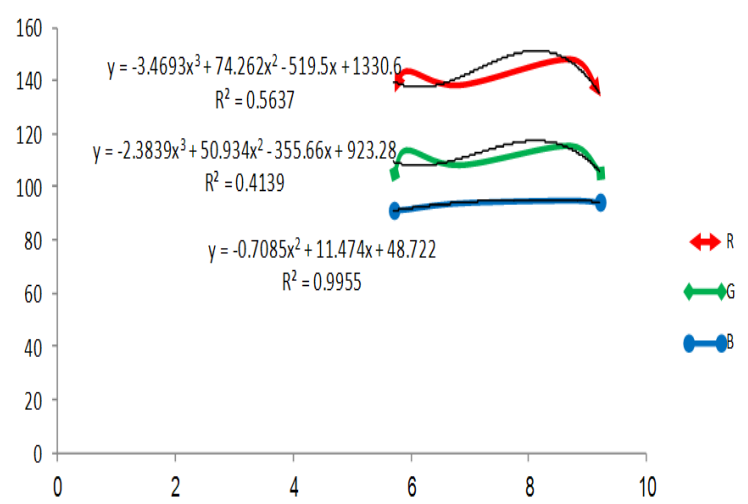

Figure 4. Diagram of relationships between Brix and RGB at Tamar stage

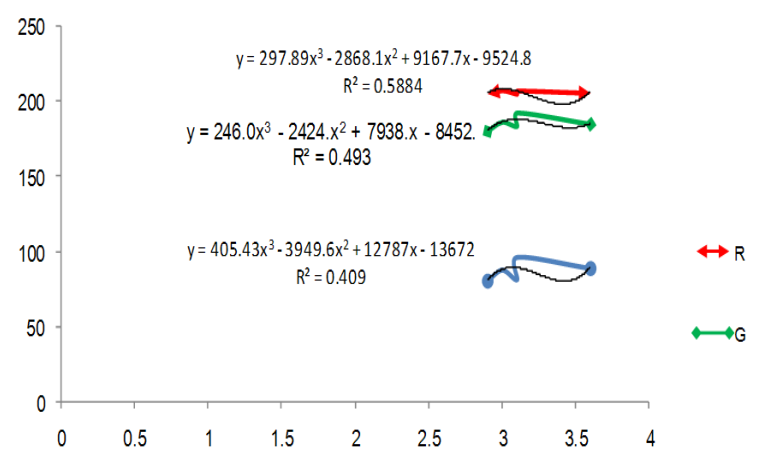

Figure 6. Diagram of relationships between Brix and RGB at Khalal stage

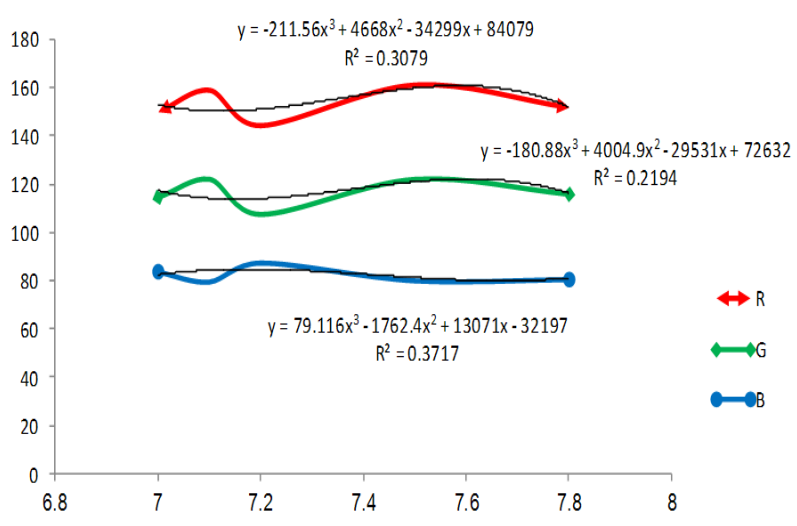

Figure 5. Diagram of relationships between Brix and RGB at Rotab stage

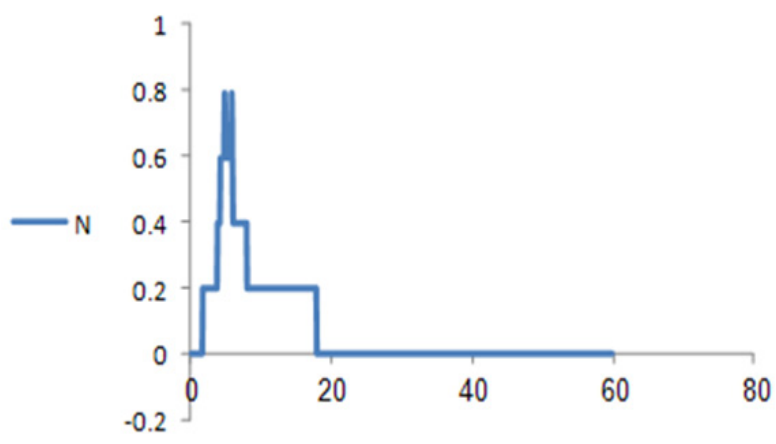

Figure 7. Relaxation curve of Khalal

In another comparison, 10 samples were selected for each stage of maturity and weighed by a digital balance with 0.01 gr accuracy. The surface areas of samples were measured by image processing. According to table 7 and 8 , it is obvious that the results from digital balance and those of obtained from software are the same. From the view point of weight and surface area, there were not significant differences between Khala and Rotab but 
Tamar was significantly different from Rotab and Khalal. According to the same results, it can be concluded that projected area of fruit in the image can be used instead of weight factor.

Table7. Result of Duncan test for weight

\begin{tabular}{cccc}
\hline Treatment & $\mathrm{N}$ & \multicolumn{2}{c}{ Subset for alpha $=0.05$} \\
\cline { 3 - 4 } Tamar & 10 & 6.0050 & \multicolumn{1}{c}{2} \\
\cline { 3 - 4 } Rotab & 10 & & 8.8800 \\
Khalal & 10 & & 8.9670 \\
Sig. & & 1.000 & .803 \\
\hline
\end{tabular}

Table 8. Result of Duncan test for surface area

\begin{tabular}{cccc}
\hline \multirow{2}{*}{ Treatment } & $\mathrm{N}$ & \multicolumn{2}{c}{ Subset for alpha $=0.05$} \\
\cline { 3 - 4 } Rotab & 10 & 83258.1000 & 2 \\
\cline { 3 - 4 } Khalal & 10 & 83354.4000 & \\
Tamar & 10 & & 84023.0000 \\
Sig. & & .673 & 1.000 \\
\hline
\end{tabular}

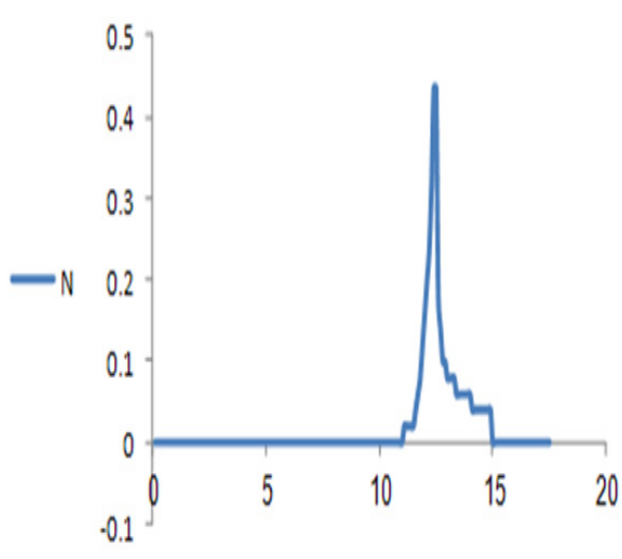

Figure 8. Relaxation curve of Rotab

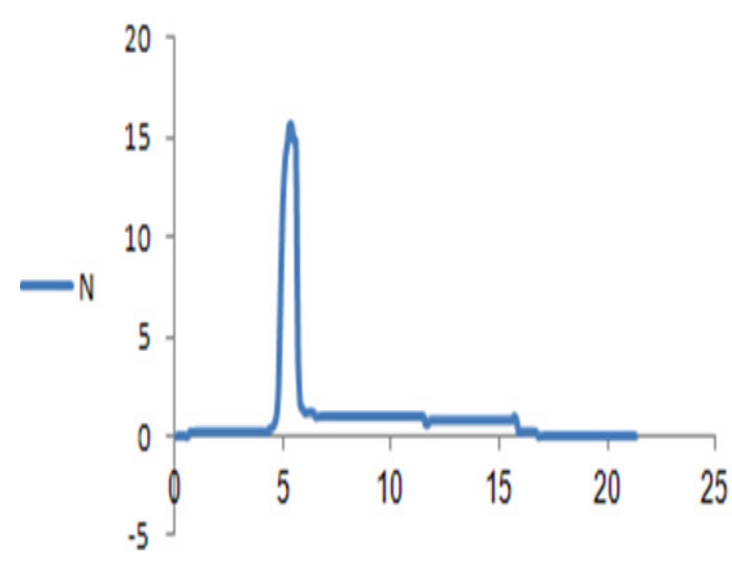

Figure 9. Relaxation curve of Tamar

Impact tests were performed on 8 samples. Equivalent energies for impact force at the angles of $30^{\circ}, 45^{\circ}, 60^{\circ}$ and $90^{\circ}$ were $0.00145,0.00317,0.0054$ and $0.0108 \mathrm{~J}$ respectively. In Khalal, skin and flesh of fruit remained intact in all treatments (pendulum release angles). In Rotab however, at the pendulum release angles of $45^{\circ}$ and $60^{\circ}$, two samples were damaged insignificantly and at the pendulum release angles of $90^{\circ}$, five samples were damaged slightly. In Tamar, the skin was puffed; and after the pendulum impact, the puffed area was flattened and then its original shape was restored. There were not any damaged samples at pendulum release angles of $30^{\circ}, 45^{\circ}$ and $60^{\circ}$ But the puffed skin of two samples were cut insignificantly at pendulum release angle of $90^{\circ}$.

In Drop test, Equivalent energies for Khalal, Rotab and Tamar at the height of $50 \mathrm{~cm}$ were $0.0445,0.0415$ and $0.03 \mathrm{~J}$ respectively. All samples remained intact. Fruits subjected to impact were damaged more than those fruits that were subjected to drop. This indicates that in designing the end effectors for sorting lines, special consideration should be made in determining the force ranges, so that the damages due to impact to be minimal. Ferreira et al. (2008) used drop test and impact test to consider the strawberry fruit resistance to simulated handling. 
In compression test (crosshead speed of $200 \mathrm{~mm} \cdot \mathrm{min}^{-1}$ ), force was plotted versus time and only the peak force at $75 \%$ compression from original height of the sample was determined. While relaxation characteristics is possible to obtain from aforementioned test, but the sampling speed of the software incorporated into Instron was inadequate, so that the stepwise curve was produced and this prevented the researcher from calculating relaxation time etc. as mentioned by Mohsenin (1970). However, fast relaxation time as observed in Figures 7, 8 and 9, indicate that Date undergo somehow rapid visco-plastic flow under constant displacement; the characteristic that is undesirable from fresh product consumers' point of view and should be considered in designing packing facilities.

The textural features listed in Table 1 were analyzed. With respect to every feature, the differences between Tamar, Rotab and Khalal were significant.

\section{References}

Akar, R., \& Aydin, C. (2005). Some physical properties of gumbo fruit varieties. Journal of Food Engineering, 66, 387-393. http://dx.doi.org/10.1016/j.jfoodeng.2004.04.005

Christensen, P., Mary, L. B, Curtis, D. L., Amand, N. K., \& Martin, W. M. (2012). American Journal of Enology and Viticulture. Available on http://www.ajevonline.org/content/46/1/10.abstract

Fadel, M. A., Kurmestegy, L., Rashed, M., \& Rashed, Z. (2001). Date variety recognition and sugar content estimation via color analysis. The Second International Conference on Date Palms. Al-Ain, UAE.

Fadel, M. A., Kurmestegy, L., Rashed, M., \& Rashed, Z. (2006). Fruit Color Properties of Different Cultivars of Dates (Phoenix dactylifera, L.). Agricultural Engineering International: the CIGR Ejournal.

Ferreira, M. D., Sargent, S. A., Brecht, J. K., \& Chandler, C. K. (2008). Strawberry fruit resistance to simulated handling. Sci. Agric. (Piracicaba, Braz.), 65(5), 490-495.

Kashaninejad, M., Mortazavi, A., Safekordi A., \& Tabil, L. G. (2006). Some physical properties of pistachio

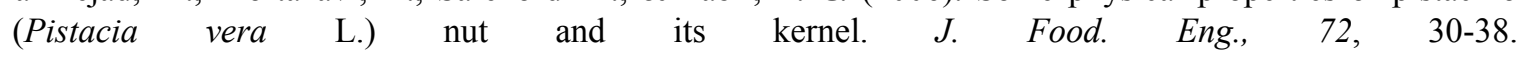
http://dx.doi.org/10.1016/j.jfoodeng.2004.11.016

Keramat, J. M., Jafari, A., Rafiee, S., Keyhani, A. R., Mirasheh, R., \& Mohtasebi, S. S. (2007). Determining some physical properties of date fruit (cv Lasht). Agric. Eng. Int.: the CIGR Ejournal.

Keramat, J., M., Jafari, A., Rafiee, S., Keyhani, A. R., Mirasheh, R., \& Mohtasebi, S. S. (2008). Determining and comparison of some physical characteristic of date fruit (Behi and Khasoei). J. Agric. Sci. Nature Resour., $15(1)$

Lee, D. J., James, K., Archibald, Yu-Chou Chang, Christopher, \& Greco, R. (2008). Robust color space conversion and color distribution analysis techniques for date maturity evaluation. Journal of Food Engineering, 88, 364-372. http://dx.doi.org/10.1016/j.jfoodeng.2008.02.023

Mohsenin, N. N. (1970). Physical properties of plant and animal materials (1st ed.). chapter 4. Gordon and Breach Science publishers. London

Myhara, R., Al-Alawi, A., Karkalas, J., \& Taylor, M. S. (2000). Sensory and textural changes in maturing Omani dates. Journal of the Science of food and agriculture, 80(15), 2181-2185. http://dx.doi.org/10.1002/1097-0010(200012)80:15<2181::AID-JSFA765>3.0.CO;2-C

Nalbandi, H., Seyedloo, S., Hajilou, J., Moghaddam, M., \& Adlipour, M. (2011). Physical properties and color characteristics of Iranian genotypes of cornelian cherry. Journal of Food Process Engineering, 34(3), 792-803. http://dx.doi.org/10.1111/j.1745-4530.2009.00434.x

Rohani, A. (1988). Date Palm, Chapter 1. University of Tehran publisher. Iran.

Safa, M., \& Khazaie, J. (2003). Determining and modeling some physical properties of pomegranate fruites of Saveh area related to peeling and packaging. Proceedings of the International Congress, Food and Environment, Izmir, Turkey.

Topuz, A. M., Topakci, M., Canakci, Akinci, I., \& Ozdemir, F. (2005). Physical and nutritional properties of four $\begin{array}{lllll}\text { orange varieties. Journal of Food Engineering, 66, 519-523. } & \text {. }\end{array}$ http://dx.doi.org/10.1016/j.jfoodeng.2004.04.024 